\title{
A ocorrência da conjunção aditiva " $e$ " no texto de divulgação sobre o Programa Ciência sem Fronteiras na Revista Tecnológica da UTFPR
}

\section{La ocurrencia de la conjunta aditiva " $y$ " en el texto de divulgación sobre el Programa Ciencia sin Fronteras en la Revista Tecnológica de la UTFPR The occurrence of the additive conjunction "and" in the text of divulgation on the Science without Borders Program in the UTFPR technological} magazine

\author{
Dra. Carina Merkle Lingnau ${ }^{1}$ \\ Dr. Juliano Desiderato Antonio ${ }^{2}$ \\ Dr. Pedro Navarro ${ }^{3}$
}

\begin{abstract}
Resumo
Na Universidade Tecnológica Federal do Paraná (UTFPR) mais de 1600 alunos participaram do Programa Ciência sem Fronteiras (CsF), sendo que esta participação está divulgada em revista de edição comemorativa da UTFPR. O objetivo deste trabalho é discutir em linhas gerais a ocorrência da conjunção aditiva E em texto de divulgação sobre o Programa Ciência sem Fronteiras na UTFPR. Como metodologia utilizamos levantamento bibliográfico e pesquisa documental. Nossas discussões têm suporte teórico em Neves (1985), Castilho (2010), Pezatti (2005), entre outros. Com base nos trechos retirados como recorte percebemos que a maior parte das ocorrências da conjunção aditiva E estão entre os sintagmas nominais e são utilizados para diferentes situações semânticas.
\end{abstract}

Palavras-Chave: aditiva; conjunção; gramática; internacionalização; uso.

\section{Resumen}

En la Universidad Tecnológica Federal de Paraná (UTFPR) más de 1600 alumnos participaron del Programa Ciencia sin Fronteras (CsF), siendo que esta participación está divulgada en una revista de edición conmemorativa de la UTFPR. El objetivo de este trabajo es discutir en líneas generales la ocurrencia de la conjunción aditiva E en texto de divulgación sobre el Programa Ciencia sin Fronteras en la UTFPR. Como metodología utilizamos levantamiento bibliográfico e investigación documental. Nuestras discusiones tienen soporte teórico en Neves (1985), Castilho (2010), Pezatti (2005), entre otros. Con base en los extractos retirados como recorte percibimos que la mayor parte de las ocurrencias de la conjunción aditiva E están entre los sintagmas nominales y se utilizan para diferentes situaciones semánticas.

Palabras claves: aditivo; conjunción; la gramática; internacionalización; uso.

\footnotetext{
1 Doutora em Letras; Universidade Tecnológica Federal do Paraná, Francisco Beltrão, Paraná, Brasil; carinadebeltrao@gmail.com.

${ }^{2}$ Doutor em Linguística e Língua Portuguesa; Universidade Estadual de Maringá; Maringá, Paraná, Brasil; prof.jdantonio@gmail.com.

${ }^{3}$ Doutor em Linguística e Língua Portuguesa; Universidade Estadual de Maringá; Maringá, Paraná, Brasil; navarro.pl@gmail.com.
} 


\begin{abstract}
At the Universidade Tecnológica Federal do Paraná (UTFPR) more than 1600 students participated in the Science without Borders Program ( $\mathrm{SwB}$ ), and this participation is published in a commemorative edition magazine of UTFPR. The objective of this work is to discuss in general terms the occurrence of the additive conjunction $\mathrm{E}$ in a text of dissemination about the Science without Borders Program in UTFPR. As methodology we use bibliographical research and documentary research. Our discussions have theoretical support in Neves (1985), Castilho (2010), Pezatti (2005), among others. Based on the sections taken as an excerpt, we notice that most occurrences of the additive conjunction AND are between the noun phrases and are used for different semantic situations.
\end{abstract}

Keywords: additive; conjunction; grammar; internationalization; use.

\title{
1. Introdução
}

Pela primeira vez na história da educação brasileira estabeleceu-se um programa de internacionalização em massa para sete tipos diferentes de sujeitos: alunos de graduação, alunos de doutorado, alunos de pós-doutorado, jovens talentos, treinamento de especialistas em empresas e pesquisadores visitantes.

De acordo com o decreto 7642 de 2011 é instituído o Programa Ciência sem Fronteiras $(\mathrm{CsF})$, um programa que busca promover a consolidação, expansão e internacionalização da ciência e tecnologia, da inovação e da competitividade brasileira por meio do intercâmbio e da mobilidade internacional. A iniciativa é resultado de esforço conjunto dos Ministérios da Ciência, Tecnologia e Inovação (MCTI) e do Ministério da Educação (MEC), por meio de suas respectivas instituições de fomento - Conselho Nacional de Desenvolvimento Científico e Tecnológico (CNPq) e Coordenação de Aperfeiçoamento de Pessoal de Nível Superior (Capes), além das Secretarias de Ensino Superior e de Ensino Tecnológico do MEC.

O projeto prevê a utilização de até 101 mil bolsas em quatro anos para promover intercâmbio, de forma que alunos de graduação e pós-graduação façam estágio no exterior com a finalidade de manter contato com sistemas educacionais competitivos em relação à tecnologia e inovação. Além disso, busca atrair pesquisadores do exterior que queiram se fixar no Brasil ou estabelecer parcerias com os pesquisadores brasileiros nas áreas prioritárias definidas no Programa, bem como criar oportunidade para que pesquisadores de empresas recebam treinamento especializado no exterior (BRASIL, 2015a).

A Universidade Tecnológica Federal do Paraná (UTFPR) é uma instituição recente enquanto universidade, completando no ano de 2020, apenas 15 anos de inserção no ensino superior. Seu início foi como ensino técnico desde 1909, momento de sua fundação como a então denominada Escola de Aprendizes Artífices do Paraná. Em 1937 passou a ser chamada 
de Liceu Industrial do Paraná e somente em 1942 conquistou o status de Escola Técnica de Curitiba.

No ano de 1959 passou a ser instituição federal nomeada Escola Técnica Federal do Paraná para então, no ano de 1978 tornar-se Centro Federal de Educação Tecnológica do Paraná (CEFET-PR) até 2005, quando passou a ser universidade. Atualmente a UTFPR distribui seus campi em 13 municípios do estado do Paraná.

Como primeira e única universidade tecnológica do Brasil ela vem se identificando com outras instituições tecnológicas de países como França, Alemanha, Estados Unidos da América (EUA) e Argentina (UTFPR, 2015b). Desde 2012 até quando durou o programa os alunos da UTFPR têm participado do Programa CsF e mais de 1600 alunos da instituição participaram do Programa. Quanto à importância desse idioma, Lacoste (2005, p.7-8) aponta:

\begin{abstract}
[...] em nossos dias, aquilo que podemos chamar de neo-imperialismo não tem mais necessidade de conquistar territórios para exercer sua dominação econômica e cultural. Isso vale sobretudo para aquela que se tornou a hiperpotência, a América (ou mais exatamente os Estados Unidos da América). Ocorre que, por ser antiga herança colonial, sua língua é o inglês, a língua que também é oficial em vários dos países que foram colonizados pelos britânicos. Em acréscimo, de algumas décadas para cá, o inglês também se propaga no plano mundial como a língua da globalização, bem como a língua da União Européia, que engloba cerca de trinta Estados de línguas diferentes e que tem necessidade de uma língua comum, ao menos em meio às categorias sociais mais "globalizadas" de sua população.
\end{abstract}

Assim, verificamos que cada vez mais precisamos aumentar nosso conhecimento para sermos considerados competentes no mercado de trabalho. O conhecimento de outras línguas vem sendo mais exigido na vida acadêmica, durante os anos de ensino superior, e quase obrigatoriamente em mestrados e doutorados, assim como na vida profissional, em que empresas multinacionais procuram funcionários já com domínio de uma ou mais línguas estrangeiras; no entanto, percebe-se que poucos acadêmicos possuem habilidades nesta área.

A UTFPR é a primeira universidade paranaense com mais alunos no Programa Ciência sem Fronteiras. Depois vem a Universidade Federal do Paraná (UFPR) e a Universidade Estadual de Maringá (UEM). No quesito área específica a UTFPR fica em terceiro lugar para as bolsas de engenharia e outras áreas tecnológicas. Dentre todas as áreas a UTFPR é a décima instituição a enviar alunos para o Programa CsF (UTFPR, 2015a). 


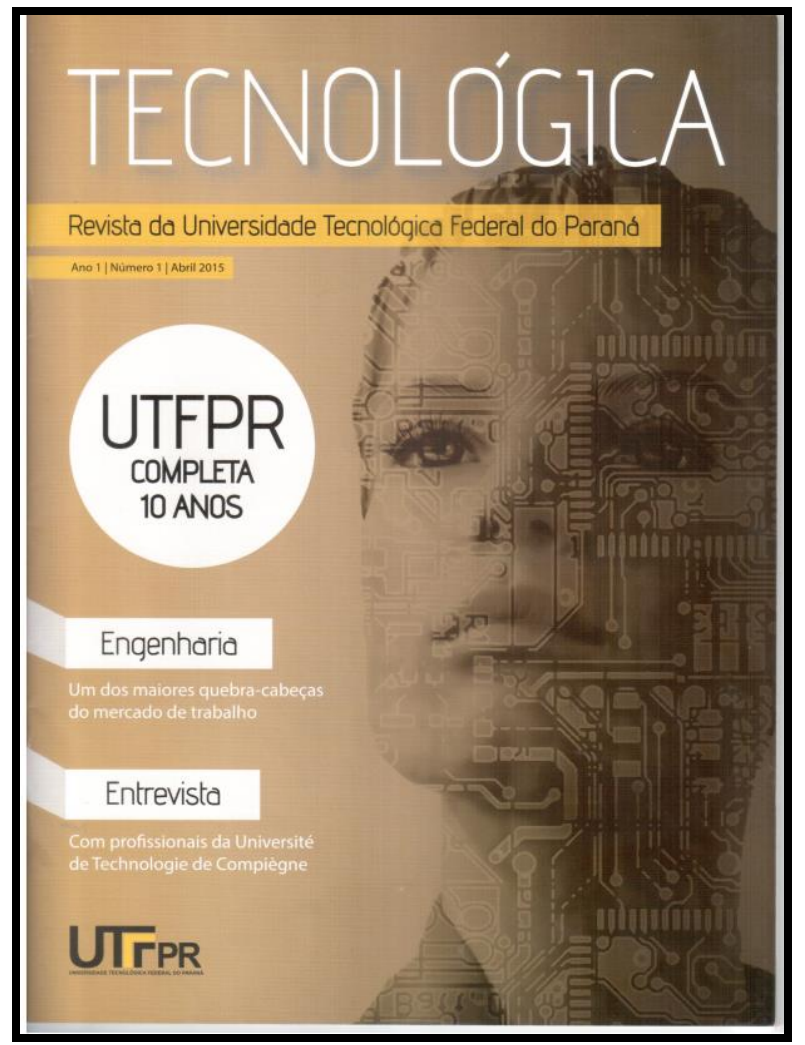

Figura 1 - Revista Tecnológica UTFPR

Fonte: http://portal.utfpr.edu.br/comunicacao/produtos/revista-tecnologica

As pesquisas em torno dos textos elaborados sobre o Programa na UTFPR são recentes, assim com a intenção de verificarmos a ocorrência da conjunção coordenada $E$ ao longo do texto escrito na Revista Tecnológica UTFPR intitulado UTFPR sem fronteiras partimos da compreensão da conjunção como "técnica para melhorar um texto, consiste em combinar duas ou mais orações através de mecanismos de ligação" (PEZATTI, 2005, p.1) e buscamos na conjunção aditiva $\mathrm{E}$ as relações semânticas realizadas e por nós compreendidas.

\section{Conjunções coordenadas}

De acordo com Castilho (2010, p.346) as coordenadas estão ligadas à concordância. Já Pezatti (2005, p.2) entre outras coisas, afirma que "a coordenação é um processo sintático que consiste em combinar duas ou mais orações, do mesmo nível estrutural, por meio de mecanismos de ligação". Castilho (2010, p.246) comenta que

Apolônio Díscolo (séc. I d.C./1987) descreve a similitude das terminações flexionais constatáveis entre o adjetivo e o substantivo, e entre o verbo e o substantivo-sujeito como uma relação de igualdade. Para denominar tal relação, vale-se de diversos verbos prefixados por syn-, preposição grega que corresponde à latina cum (>co, em 
coordenada), adequada a ressaltar que os termos relacionados apresentam-se em pé de igualdade, concordes entre si.

Esses dois autores demonstram que as coordenadas combinam e inter-relacionam elementos da língua portuguesa. Nesse sentido, verificamos Fortes (2012, p.286-287) quando comenta sobre o papel das conjunções para os gramáticos Prisciano e Apolônio Díscolo,

\begin{abstract}
deve-se saber que, caso se anteponha uma conjunção a uma palavra de caso, é necessário coordenar uma outra palavra de caso, e o verbo referir-se às duas, como em 'et Dionysius loquitur et Trypho' ["tanto Dionísio fala quanto Trifão"], 'et Apollonius scripsit et ego' ["tanto Apolônio quanto eu escrevemos"], 'et uigilans proficit et legens ["progride tanto vigiando quanto lendo"]; também ao contrário, caso se anteponha uma conjunção a um verbo, é necessário que outro verbo se associe a ela e ambos se refiram a uma palavra de caso, como 'et scribit et legit Trypho' ["Trifão tanto lê quanto escreve"], 'et pugnat et uincit Aeneas' ["Eneias tanto luta quanto vence"].
\end{abstract}

Historicamente, percebemos a noção de relação entre as partes quando se pensa em conjunções coordenadas. Nesse sentido, Neves (1985, p.63) afirma que

o traço central que define dois segmentos entre os quais ocorre uma conjunção coordenativa é o da exterioridade: o segundo segmento é, sintaticamente, externo ao primeiro, e a conjunção coordenativa é bloqueador da oposição do segundo segmento ao primeiro. Assim, como invariância para definir o valor da conjunção coordenativa.

Dessa forma, observamos que todos os autores trabalham com o conceito de coordenação como inter-relação, como processo que estabelece associação entre partes de um trecho escrito ou falado.

\title{
2.1. A conjunção aditiva $E$
}

Castilho (2010, p.349-350) se vale das propriedades sintáticas e discursivas da conjunção aditiva $E$, nesse sentido explica que a "conjunção $E$ em termos de propriedades sintáticas, coordena os mais variados segmentos, unindo elementos de composição de uma palavra, constituintes do sintagma, sintagmas, sentenças. Já no quesito propriedade discursiva Castilho (2010, p.350) afirma que

no início de enunciados, $e$ preserva seu valor latino original, de adicionador de atos de fala, ocorrendo nos seguintes ambientes: 1. Unindo turnos conversacionais, funcionando como marcador de alternância de turnos[...]; 2. Adicionando temas, concorrendo para a progressão temática [...]; 3. Adicionando sentenças interrogativas $[\ldots] ;$ 4. Acumulando um conjunto de enunciados, nos 
polissíndetos ${ }^{4}[\ldots]$; 5. Finalizando um enunciado, implicitando que "o resto já se sabe" por meio de expressões fixas.

Pezatti (2005, p.5) discute as relações semânticas estabelecidas pela coordenação aditiva. A autora afirma que "a relação de adição entre orações, no português falado, é geralmente estabelecida por meio de justaposição ou por meio de conjunção aditiva $e$ ". Pezatti (2005,p.5) ainda declara que

\begin{abstract}
é conveniente distinguir dois tipos de adição, o simétrico e o assimétrico.[...] $\mathrm{Na}$ coordenação simétrica, cada membro da adição é independente do que o segue e do que o precede em qualquer parte da sentença completa. Em decorrência disso, cada membro retém sua integridade e nenhum adiciona significados ao outro, nem uma cadeia de membros precedentes torna o último um membro ininteligível. Na coordenação assimétrica, por outro lado, o conjunto é, num certo sentido, maior do que a soma das partes. Além de encadeamento, o conjunto inclui a idéia de que cada membro ligado leva ao outro e que nenhum seria verdadeiro, se os que o precedem não o fossem também. Extraídos do contexto, os membros não reteriam a junção causal ou implicacional, perdendo-se, assim, parte do significado de todo o enunciado.
\end{abstract}

Além disso, Pezatti (2005, p.13) ainda traz outros valores semânticos da conjunção $\boldsymbol{E}$. A autora contribui com o seguinte pensamento, dizendo que

na adição de orações, a conjunção $E$ opera como o modo não-marcado de conexão na organização textual, já que veicula menos significado que as outras conjunções aditivas ou e mas . [...] a conjunção $E$ também poderia ser perfeitamente parafraseável por um tipicamente conclusivo, como portanto.

Assim, tendo por base as perspectivas sintáticas, discursivas e semânticas da conjunção coordenativa $E$ analisamos seu uso no texto "UTFPR sem Fronteiras".

\title{
2.2. A conjunção aditiva $E$ no texto "UTFPR sem Fronteiras"
}

Para examinar a ocorrência da conjunção aditiva $E$ no texto "UTFPR sem Fronteiras" utilizamos a terminologia adotada por Castilho (2010, p.349-350). O autor explica a nomenclatura da seguinte forma,

Sentença ou oração é a unidade da sintaxe estruturada por um verbo que seleciona seu sujeito e seus complementos. [...] sintagma é uma unidade da análise sintática composta de um núcleo (um verbo, um nome, um adjetivo, um advérbio, uma preposição), uma margem esquerda (preenchida pelos Especificadores) e uma

\footnotetext{
${ }^{4}$ De acordo com o dicionário online Michaelis, polissíndeto é um sm (gr polysýndeton) Ret Figura que consiste na ligação de uma série de termos coordenados por uma mesma conjunção: Temos braços e cérebros e terra $\boldsymbol{e}$ riquezas latentes. Var: polissíndeton. Antôn: assíndeto.
} 
margem direita (preenchida pelos complementizadores). A designação do sintagma dependerá da classe da palavra que preenche seu núcleo, havendo: sintagma nominal, verbal, adjetival, adverbial, preposicional (CASTILHO, 2010, p.691-692).

Assim, elaboramos um quadro mostrando um recorte das ocorrências da conjunção aditiva $E$ para em seguida fazermos os comentários.

\begin{tabular}{|c|c|}
\hline \multicolumn{2}{|c|}{ Quadro 1 - Ocorrências da conjunção aditiva E } \\
\hline OCORRÊNCIAS & TRECHO \\
\hline 1. $\quad$ sintagmas nominais & Conrado Henneberg $\boldsymbol{E}$ Nicolas Brugnolo \\
\hline 2. sintagmas nominais & competências $\boldsymbol{E}$ habilidades \\
\hline 3. $\quad$ sintagmas nominais & pesquisadores $\boldsymbol{E}$ estudantes \\
\hline 4. sentenças & Ampliar o conhecimento [...] $\boldsymbol{E}$ atrair jovens [...] \\
\hline 5. $\quad$ sintagmas nominais & científicos $\boldsymbol{E}$ investigadores \\
\hline 6. $\quad$ sintagmas adjetivais & financeiras $\boldsymbol{E}$ outras \\
\hline 7. sentenças & "Era uma forma $[\ldots] \boldsymbol{E}$ consequentemente nos ajudar $[\ldots] "$ \\
\hline 8. $\quad$ sintagmas nominais & Poluição Ambiental $\boldsymbol{E}$ Climatologia \\
\hline 9. $\quad$ sintagmas nominais & $\begin{array}{l}\text { Universitat de Girona } \boldsymbol{E} \text { a Escuela Politecnica La Almunia de } \\
\text { Donã Godina }\end{array}$ \\
\hline 10. sintagmas nominais & agosto de $2013 \boldsymbol{E}$ dezembro de 2014 \\
\hline 11. sentenças & É um obstáculo $[\ldots] \boldsymbol{E}$ é um limitante $[\ldots]$ \\
\hline 12. sentenças & Alguns dos planos do aluno [...] $\boldsymbol{E}$ ter uma experiência [...] \\
\hline
\end{tabular}

Com base nos trechos retirados como recorte percebemos que a maior parte das ocorrências da conjunção aditiva $E$ estão entre os sintagmas nominais e são utilizados para diferentes situações semânticas.

Desse modo, apresentam-se a seguir os enunciados, presentes no corpus de análise, dotados de uma carga semântica que vão além da adição:

04) Criado em julho de 2011 pelo governo federal, o programa já enviou cerca de 71 mil brasileiros ao exterior com o objetivo de investir na formação de pessoal altamente qualificado nas competências e habilidades necessárias para o avanço da sociedade do conhecimento, aumentar a presença de pesquisadores e estudantes de vários níveis em instituições de excelência no exterior, promover a inserção internacional das instituições brasileiras pela abertura de oportunidades semelhantes para cientistas e estudantes estrangeiros, ampliar o conhecimento inovador de pessoas das indústrias tecnológicas $\boldsymbol{E}$ atrair jovens talentos científicos e investigadores altamente qualificados para trabalhar no Brasil. (valor semântico de adição)

07) "Era uma forma de matar um pouco a saudade do Brasil $\boldsymbol{E}$ consequentemente nos ajudar uns aos outros nas dificuldades encontradas". (valor semântico de consequência) 
11) "É um obstáculo a gente só ofertar aulas em português. Isso dificulta a realização de projetos em conjunto $\boldsymbol{E}$ é um limitante no processo de ampliar as trocas e parcerias com universidades estrangeiras". (valor semântico de consequência)

12) Alguns dos planos do aluno são cursar disciplinas da área de engenharia mecânica, tanto as compatíveis como as que não fazem parte da grade do curso da UTFPR, $\boldsymbol{E}$ ter uma experiência profissional na Austrália. (valor semântico de consequência)

A partir das amostras é possível verificar que entre as sentenças analisadas apenas na amostra 04 a conjunção aditiva $\boldsymbol{E}$ assumiu valor semântico apenas de adição, nas outras sentenças observamos valor semântico de consequência, o que nos leva a pensar como Neves (1985, p.63) quando afirma que

\footnotetext{
a partir dessas invariâncias pode-se tentar responder pelas diversas ocorrências de cada um desses elementos, incursionando, então, pelo terreno da análise semântica do enunciado total e pelas considerações de suas condições de produção. Temos como certo que essas caracterizações se fazem em terreno fluído.
}

Assim, verificamos que as possibilidades semânticas da conjunção coordenada $E$ são ilimitadas e que é interessante observar o valor polissêmico desta conjunção e a perspectiva de outros valores semânticos para a conjunção coordenada $\boldsymbol{E}$.

\section{Conclusões}

Por meio desse recorte, confirma-se que a conjunção coordenada $\boldsymbol{E}$ pode assumir valores semânticos para além da adição. Pode-se dizer, então, que a conjunção coordenativa $\boldsymbol{E}$ no texto “UTFPR sem Fronteiras" apresenta valor semântico de adição na sua maior ocorrência, porém não deixa de apresentar outros valores semânticos. Dessa maneira, é possível verificar a importância dos estudos de Neves (1985), Castilho (2010) e Pezatti (2005) ao avançarem a discussão sobre a conjunção coordenada $\boldsymbol{E}$ para além das propriedades sintáticas. Assim, percebemos a dimensão dos trabalhos que envolvem a gramática discutindo a conjunção coordenada $\boldsymbol{E}$ que verifica não só a natureza estática da língua, mas a natureza dessas relações convidando aprendizes e mestres a refletir sobre o uso da língua. 


\section{Referências}

BRASIL. Decreto $n$. 7642, de 13 de dezembro de 2011. Disponível em: http://www.planalto.gov.br/ccivil_03/_Ato2011-2014/2011/Decreto/D7642.htm. Acesso em: 30 jan. 2019.

BRASIL. Programa Ciência sem Fronteiras. Disponível em: http://www.cienciasemfronteiras.gov.br/web/csf. Acesso em: 30 set. 2015 b.

CASTILHO, A. T.; Nova Gramática do Português Brasileiro. 1ª ed. São Paulo: Editora Contexto, 2010.

FORTES, F.S. Sintaxe greco-romana: Prisciano de Cesareia e Apolônio Díscolo na história do pensamento gramatical antigo. 2012.406f. Tese (Doutorado em Linguística) - Instituto de Estudos da Linguagem, Universidade Estadual de Campinas, Campinas, SP. 2012.

POLISSÍNDETO. In: DICIONÁRIO Michaelis. Disponível em: http://michaelis.uol.com.br/moderno/portugues/index.php?lingua=portuguesportugues\&palavra=poliss\%EDndeto. Acesso em: 16 nov. 2015.

NEVES, M. H. M.; O estatuto das chamadas conjunções coordenativas no sistema do português. Alfa (ILCSE/UNESP), São Paulo, v. 29, p. 59-66, 1985.

PEZATTI, E. G.; Coordenando orações na língua portuguesa. Museu da Língua Portuguesa . São Paulo: Portal da Língua Portuguesa - Língua e literatura, 2005 (publicação em mídia).

UNIVERSIDADE TECNOLÓGICA FEDERAL DO PARANÁ. Ciência sem Fronteiras. Disponível em: http://www.utfpr.edu.br/estrutura-universitaria/diretorias-degestao/dircom/noticias/noticias/ciencia-sem-fronteiras-2. Acesso em 30 set.2015a.

UNIVERSIDADE TECNOLÓGICA FEDERAL DO PARANÁ. Revista Tecnológica. Ano 1. Número $1.2015 . \quad$ Abril Disponível em: http://portal.utfpr.edu.br/comunicacao/produtos/revista-tecnologica/revista-tecnologicaedicao-01/view Acesso em 30 jan.2019. 